\title{
The Impact of Rate Reduction and Increased Loudness on Fundamental Frequency Characteristics in Dysarthria
}

\author{
Kris Tjaden $^{a}$ Greg Wilding ${ }^{b}$ \\ a Department of Communicative Disorders and Sciences, and ${ }^{b}$ Department of Biostatistics, University at Buffalo, \\ Buffalo, N.Y., USA
}

\section{Key Words}

Dysarthria $\cdot$ Fundamental frequency $\cdot$ Speaking rate $\cdot$ Loudness

\begin{abstract}
Objective: This study examined the extent to which articulatory rate reduction and increased loudness were associated with adjustments in utterance-level measures of fundamental frequency $\left(\mathrm{F}_{0}\right)$ variability for speakers with dysarthria and healthy controls that have been shown to impact on intelligibility in previously published studies. More generally, the current study sought to compare and contrast how a slowerthan-normal rate and increased vocal loudness impact on a variety of utterance-level $F_{0}$ characteristics for speakers with dysarthria and healthy controls. Patients and Methods: Eleven speakers with Parkinson's disease, 15 speakers with multiple sclerosis, and 14 healthy control speakers were audio recorded while reading a passage in habitual, loud, and slow conditions. Magnitude production was used to elicit variations in rate and loudness. Acoustic measures of duration, intensity and $F_{0}$ were obtained. Results and Conclusions: For all speaker groups, a slower-than-normal articulatory rate and increased vocal loudness had distinct effects on $\mathrm{F}_{0}$ relative to the habitual condition, including a tendency for measures of $F_{0}$ variation to be greater in the loud condition and reduced in the slow condition. These results suggest implications for the treatment of dysarthria.
\end{abstract}

Copyright ๑ 2010 S. Karger AG, Basel

\section{KARGER}

Fax +41613061234 E-Mail karger@karger.ch www.karger.com
(C) 2010 S. Karger AG, Basel

\section{Introduction}

The contribution of fundamental frequency $\left(\mathrm{F}_{0}\right)$ to speech intelligibility has been examined in studies of normal and disordered speech, including studies of dysarthria [1-8]. These studies suggest that sentences or phrases characterized by relatively greater $F_{0}$ variation, as indexed by measures such as $\mathrm{F}_{0}$ range or $\mathrm{F}_{0}$ standard deviation, tend to be associated with relatively better speech intelligibility. Spitzer et al. [6], for example, used speech resynthesis to flatten the $\mathrm{F}_{0}$ contour of phrases produced by a neurologically normal speaker. Phrases for which the intonation contour had been flattened were less intelligible compared to the original phrases for which the $\mathrm{F}_{0}$ contour was unaltered. Relatedly, Bunton [9] explored the contribution of $\mathrm{F}_{0}$ to vowel identity for speakers with Parkinson's disease (PD) and healthy controls. Speech resynthesis was used to flatten or enhance $\mathrm{F}_{0}$ contours. Results indicated that the enhanced $\mathrm{F}_{0}$ condition was associated with improved vowel identification accuracy for words produced by speakers with PD.

As illustrated by Bunton [9], one approach to investigating the contribution of $\mathrm{F}_{0}$ to intelligibility in dysarthria is to manipulate $F_{0}$ using speech resynthesis $[3,9$, 10]. These types of controlled studies have yielded much valuable information, but it also would seem important to pursue parallel studies investigating the extent to which speakers with dysarthria actually produce the

Department of Communicative Disorders and Sciences

University at Buffalo, 122 Cary Hall, 3435 Main Street

Buffalo, NY 14214 (USA)

Tel. +1 716829 5564, Fax +1 716829 3979, E-Mail Tjaden@buffalo.edu 
kinds of $\mathrm{F}_{0}$ adjustments that have been linked to intelligibility in studies employing speech resynthesis. Thus, the present study explored the extent to which two behavioral therapy techniques for dysarthria were associated with $\mathrm{F}_{0}$ adjustments that have the potential to impact on intelligibility. By investigating two therapeutic techniques in the same speakers with dysarthria, the present study also helps to address the need for group studies comparing the relative merits of intervention techniques [11].

Rate reduction and increased vocal loudness are widely used in the treatment of dysarthria [12]. Both techniques have the potential to improve intelligibility, although a slower-than-normal rate has been shown in at least some studies to have quite variable effects on intelligibility in dysarthria, and studies investigating increased loudness in dysarthria have only recently begun to include formal, quantitative measures of intelligibility. Studies from our lab investigating rate and loudness effects in dysarthria have focused on segmental adjustments associated with these therapeutic techniques [13, 14]. As reviewed below, other studies have explored the effects of increased loudness and rate reduction on $\mathrm{F}_{0}$, albeit not in the form of group comparison studies.

The impact of increased loudness on $\mathrm{F}_{0}$ characteristics for neurologically normal speakers and speakers with dysarthria has been examined in studies using a variety of speech materials [e.g., 15-19; for a review of dysarthria studies, see 12]. These studies indicate a tendency for increased loudness to be associated with an increase in mean $\mathrm{F}_{0}$ as well as increased $\mathrm{F}_{0}$ variation or range. It is reasonable to speculate that this enhanced prosodic variation helps to explain the improved intelligibility accompanying increased vocal loudness reported for at least some speakers with dysarthria, although the appropriate empirical studies have yet to be conducted. Group dysarthria studies investigating $\mathrm{F}_{0}$ adjustments accompanying increased vocal loudness have mostly focused on PD, however, and research suggests the importance of studying a variety of populations, as rate and loudness manipulations may not uniformly affect speech characteristics for all neurological diagnoses and dysarthrias [20-22].

$\mathrm{F}_{0}$ adjustments associated with a slower-than-normal articulatory rate have not been studied much in dysarthria, at least in studies where rate effects can be readily teased apart from other factors or were the primary focus of study [23, 24]. For example, Wang et al. [24] reported descriptive measures of $\mathrm{F}_{0}$ in the form of means and standard deviations for sentences produced at habitual, fast, and slow rates by speakers with dysarthria secondary to traumatic brain injury. Even for neurologically normal talkers, $\mathrm{F}_{0}$ characteristics associated with a slower-thannormal articulatory rate are not well understood, and speaker numbers and experimental speech materials in existing studies are generally quite limited. Nonetheless, the available published studies suggest a tendency for a slower-than-normal articulatory rate to be associated with a lower mean $\mathrm{F}_{0}$, lower maximum $\mathrm{F}_{0}$, and reduced $\mathrm{F}_{0}$ variation [15, 25-27]. This latter finding is especially interesting and suggests the possibility that a slowerthan-normal rate may be associated with $\mathrm{F}_{0}$ adjustments potentially detrimental to intelligibility.

In summary, the purpose of the current study was to examine the extent to which two behavioral therapy techniques for dysarthria were associated with $\mathrm{F}_{0}$ adjustments that have the potential to impact on intelligibility. More generally, the present study sought to compare and contrast the impact of a slower-than-normal articulatory rate and increased loudness on a variety of $\mathrm{F}_{0}$ measures for a reading passage produced by individuals with dysarthria secondary to PD or multiple sclerosis (MS).

\section{Methods}

\section{Speakers}

A total of 40 speakers were studied. The MS group was comprised of 5 men and 10 women ranging in age from 25 to 62 years (mean age $=49$ years; $\mathrm{SD}=10$ ), the $\mathrm{PD}$ group was comprised of 6 men and 5 women ranging in age from 42 to 74 years (mean age $=61$ years; $\mathrm{SD}=11$ ), and the control group was comprised of 7 men and 7 women ranging in age from 20 to 72 years (mean age $=54$ years; $\mathrm{SD}=14$ ). Supralaryngeal adjustments associated with increased loudness and rate reduction have been previously reported for a larger group of speakers [13, 14]. Additional details regarding inclusionary criteria may be found in these studies $[13,14]$.

As summarized in tables 1 and 2, a dysarthria diagnosis, prominent deviant perceptual characteristics, and an estimate of dysarthria severity were identified for individuals with MS and PD based on consensus, auditory-perceptual judgments of 3 speech-language pathologists. Scaled estimates of intelligibility for the 'Grandfather Passage' also were provided by 5 graduate students in speech-language pathology for the purpose of characterizing speech severity. Direct magnitude estimation was used to obtain a relative ranking of intelligibility, with higher scale values indicating relatively better intelligibility and lower scale values indicating relatively poorer intelligibility. Scaled intelligibility estimates in tables 1 and 2 represent the geometric mean for the 5 listeners. Intelligibility was not estimated for PDF2 due to technical difficulties.

Speech Sample and Speaking Task

Participants were audio recorded while reading the 'John Passage', a 192-word passage developed to include a variety of con- 
Table 1. Speaker characteristics for participants diagnosed with MS

\begin{tabular}{|c|c|c|c|c|c|c|}
\hline $\begin{array}{l}\text { Subject } \\
\text { code }\end{array}$ & $\begin{array}{l}\text { Age } \\
\text { years }\end{array}$ & $\begin{array}{l}\text { Years } \\
\text { after } \\
\text { diagnosis }\end{array}$ & $\begin{array}{l}\text { Dysarthria } \\
\text { diagnosis }\end{array}$ & $\begin{array}{l}\text { Dysarthria } \\
\text { severity }\end{array}$ & Deviant perceptual characteristics & $\begin{array}{l}\text { Scaled } \\
\text { intelligi- } \\
\text { bility }\end{array}$ \\
\hline MSF1 & 60 & 12 & spastic & moderate & strain-strangled, slow rate, short phrases & 29 \\
\hline MSF2 & 42 & 8 & spastic-ataxic & mild & low pitch, imprecise consonants, excess and equal stress & 238 \\
\hline MSF3 & 33 & 5 & spastic & moderate & stain-strangled, slow rate, voice tremor & 57 \\
\hline MSF4 & 50 & 9 & ataxic & mild/moderate & hyponasal, excess and equal stress, monopitch & 70 \\
\hline MSF5 & 41 & 12 & ataxic & mild/moderate & hyponasal, irregular articulatory breakdown, harsh & 100 \\
\hline MSF6 & 56 & 7 & spastic & mild & low pitch, harsh, slow rate & 183 \\
\hline MSF7 & 59 & 15 & ataxic & moderate & hyponasal, excess and equal stress, imprecise consonants & 65 \\
\hline MSF8 & 25 & 5 & spastic-ataxic & moderate & excess and equal stress, slow rate, short phrases & 112 \\
\hline MSF9 & 50 & 9 & ataxic & moderate & slow rate, imprecise consonants, irregular articulatory breakdown & 61 \\
\hline MSF10 & 54 & 5 & spastic & mild & slow rate, strain-strangled, pitch breaks & 241 \\
\hline MSM2 & 45 & 4 & ataxic & moderate & slow rate, monopitch, irregular articulatory breakdown & 91 \\
\hline MSM3 & 58 & 8 & spastic & mild & strain-strangled, harsh & 170 \\
\hline MSM5 & 62 & 5 & ataxic & mild & excess and equal stress, harsh, voice tremor & 168 \\
\hline MSM6 & 47 & 2 & ataxic & mild & hyponasal, imprecise consonants, voice tremor & 97 \\
\hline MSM7 & 48 & 21 & ataxic & moderate & hyponasal, monopitch, monoloud & 74 \\
\hline
\end{tabular}

Table 2. Speaker characteristics for participants diagnosed with PD

\begin{tabular}{|c|c|c|c|c|c|c|}
\hline $\begin{array}{l}\text { Subject } \\
\text { code }\end{array}$ & $\begin{array}{l}\text { Age } \\
\text { years }\end{array}$ & $\begin{array}{l}\text { Years after } \\
\text { diagnosis }\end{array}$ & $\begin{array}{l}\text { Dysarthria } \\
\text { diagnosis }\end{array}$ & $\begin{array}{l}\text { Dysarthria } \\
\text { severity }\end{array}$ & Deviant perceptual characteristics & $\begin{array}{l}\text { Scaled } \\
\text { intelligibility }\end{array}$ \\
\hline PDF1 & 42 & 6 & hypokinetic & moderate & monoloud, reduced loudness, variable rate & 146 \\
\hline PDF2 & 62 & 3 & hypokinetic & mild & imprecise consonants, slow rate & not available \\
\hline PDF3 & 50 & 3 & hypokinetic & moderate/severe & hypernasal, imprecise consonants, short rushes & 38 \\
\hline PDF4 & 72 & 9 & hypokinetic & moderate & reduced loudness, variable rate, short rushes & 115 \\
\hline PDF6 & 45 & 13 & hypokinetic & moderate/severe & fast rate, breathy voice, monoloud & 95 \\
\hline PDM1 & 69 & 12 & hypokinetic & moderate & monopitch, monoloud, reduced stress & 168 \\
\hline PDM2 & 74 & 1 & hypokinetic & mild & breathy, low pitch, slow rate & 100 \\
\hline PDM3 & 72 & 4 & hyperkinetic & mild & harsh, forced inspiration/expiration, low pitch & 178 \\
\hline PDM4 & 64 & 17 & hypokinetic & moderate & monopitch, monoloud, short rushes & 78 \\
\hline PDM5 & 60 & 8 & hypokinetic & moderate & breathy, short rushes, repeated phonemes & 70 \\
\hline PDM6 & 64 & 8 & hypo-/hyperkinetic & mild/moderate & breathy, fast rate, voice stoppages & 81 \\
\hline
\end{tabular}

sonants and vowels [13]. The present analyses were restricted to the first half of the reading passage, which is six sentences in length or 98 words and comparable in length to the 'Grandfather Passage' [11]. The reading passage was produced in habitual, loud, and slow speaking conditions. Magnitude production was used to elicit the variations in loudness and rate $[20,22,28]$. Details of the recording equipment and procedures may be found elsewhere $[13,14]$.

\section{Acoustic Analyses}

Articulatory rate was measured for each speech run using the combined waveform and wideband $(300-350 \mathrm{~Hz})$ digital spectrographic displays of CSpeechSp 4.0 [29]. A run was operationally defined as a stretch of speech bounded by silent periods between words of at least $200 \mathrm{~ms}[13,30]$. Conventional acoustic criteria were used to identify run onsets and offsets, such as stop release bursts, frication, or voicing energy. The number of syllables actually produced in each run was counted and articulatory rate was computed in syllables per second. Articulatory rates for speech runs in a given passage reading were averaged, yielding a mean value for each speaker and speaking condition for use in the statistical analysis.

Sound pressure level (SPL) was used to index variation in vocal intensity. SPL values for runs associated with a given passage reading were averaged, yielding a mean SPL for each speaker and condition. These averages were used in the statistical analyses. 


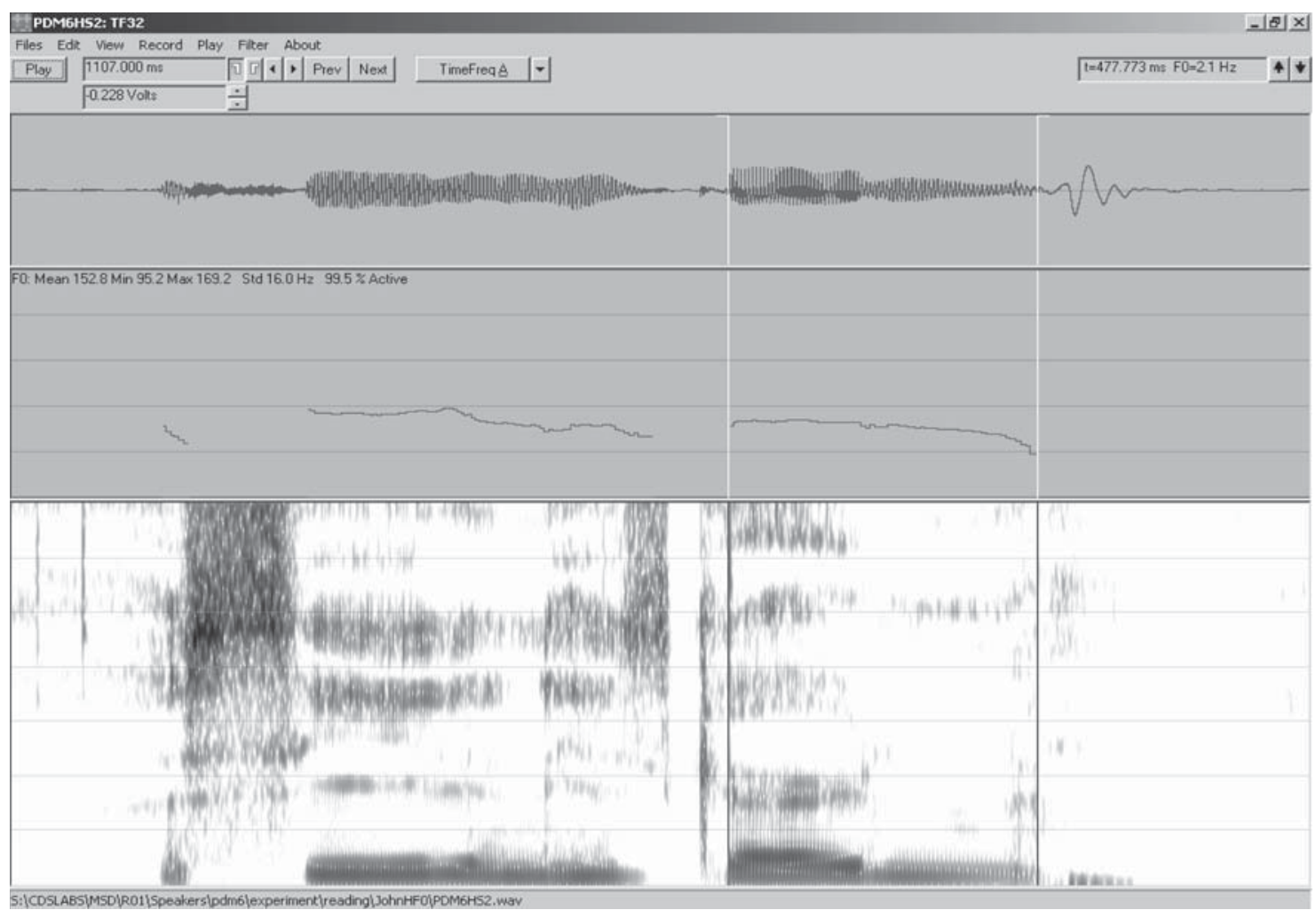

Fig. 1. The waveform, wideband digital spectrogram $(300 \mathrm{~Hz})$, and $\mathrm{F}_{0}$ trace are shown for the speech run 'a seed in his garden' spoken by a male speaker with PD in the habitual condition. Vertical cursors denote the terminal focal $\mathrm{F}_{0}$ segment. Global $\mathrm{F}_{0}$ measures for this run were as follows: $\mathrm{F}_{0}$ mean $=160 \mathrm{~Hz}, \mathrm{~F}_{0} \mathrm{SD}=19 \mathrm{~Hz}, \mathrm{~F}_{0}$ minimum $=95 \mathrm{~Hz}, \mathrm{~F}_{0}$ maximum $=195 \mathrm{~Hz}, \mathrm{~F}_{0}$ range $=100 \mathrm{~Hz}, \mathrm{~F}_{0}$ slope $=-0.028 \mathrm{~Hz} / \mathrm{ms}$.

Using TF32 [31], $\mathrm{F}_{0}$ traces were generated for each speech run and were visually inspected for errors by 2 trained research assistants unfamiliar with the purpose of the study. Computer-generated $\mathrm{F}_{0}$ tracking errors were hand-corrected on a pitch period-bypitch period basis. A broad approach was used to describe $\mathrm{F}_{0}$, based on previous studies $[15,25,32]$. Summary $F_{0}$ statistics computed for each speech run included $\mathrm{F}_{0}$ mean, standard deviation, minimum, maximum, range, interquartile range and slope. Most measures were obtained directly in TF32. Text files containing the time-by- $\mathrm{F}_{0}$ frequency values also were exported from TF32 into Excel to allow for computation of $\mathrm{F}_{0}$ range, interquartile range. $\mathrm{F}_{0}$ slope also was computed in Excel using linear regression analysis. For each speaker and condition, global $\mathrm{F}_{0}$ measures were averaged across runs for use in the statistical analyses.

Figure 1 shows the combined waveform and wideband (300$\mathrm{Hz}$ ) digital spectrographic displays for the speech run 'a seed in his garden' produced in the habitual condition by a male speaker with PD. The $\mathrm{F}_{0}$ contour also is shown. Figure 1 shows that the intonation contour is comprised of an initial, middle, and terminal segment, demarcated by vertical cursors. These components of the larger intonation contour may be referred to as focal segments [32]. A decline in the terminal portion of an intonation contour is one acoustic cue to syntactic structure in spoken English [e.g., 33, 34]. The nonterminal portion of an intonation con- tour does not necessarily show a decline, however, and this potential difference in the slope of terminal and nonterminal focal $\mathrm{F}_{0}$ segments is not captured by global $\mathrm{F}_{0}$ slope. Thus, linear regression analysis also was used to compute the slope of focal segments for comparison of nonterminal and terminal segments. For each speaker and condition, focal slope measures were averaged across terminal or nonterminal segments for use in the statistical analyses.

\section{Measurement Reliability}

Intrajudge and interjudge measurement reliability were determined for approximately $10 \%$ of the speech runs for each speaker and condition. Intrajudge reliability for SPL yielded a mean absolute error of $0.12 \mathrm{~dB}$ SPL and a Pearson product-moment correlation coefficient of 0.99 for the first and second set of measures. Interjudge reliability also yielded a correlation of 0.99 and a mean error of $0.09 \mathrm{~dB}$ SPL. Intrajudge reliability for speech run duration yielded an average measurement error of $10 \mathrm{~ms}$ and a correlation of 0.99. Interjudge reliability for speech run duration yielded a mean error of $23 \mathrm{~ms}$ as well as a correlation of 0.99 . Reliability estimates can be summarized as follows for $\mathrm{F}_{0}$ mean, standard deviation, range, minimum and maximum. For intrajudge reliability, average absolute measurement error ranged from a low of 1.87 $\mathrm{Hz}\left(\mathrm{F}_{0}\right.$ mean) to a high of $15.2 \mathrm{~Hz}$ ( $\mathrm{F}_{0}$ range). Correlation coeffi- 
Table 3. Means and standard deviations (values in parentheses) are reported for number of speech runs, articulatory rate and SPL

\begin{tabular}{|c|c|c|c|c|c|c|c|c|c|}
\hline & \multicolumn{3}{|c|}{ Speech runs, $\mathrm{n}$} & \multicolumn{3}{|c|}{ Articulatory rate, syllables/s } & \multicolumn{3}{|l|}{ SPL, dB SPL } \\
\hline & habitual & loud & slow & habitual & loud & slow & habitual & loud & slow \\
\hline Control & $11(4)$ & $12(3)$ & $24(8)$ & $4.25(0.27)$ & $3.93(0.34)$ & $2.91(0.54)$ & $81.21(2.85)$ & $86.61(2.78)$ & $80.02(3.36)$ \\
\hline MS & $17(9)$ & $19(10)$ & 32 (19) & $3.69(0.64)$ & $3.48(0.73)$ & $2.87(0.61)$ & $80.72(2.78)$ & $86.59(2.44)$ & $79.80(4.20)$ \\
\hline $\mathrm{PD}$ & $18(7)$ & $16(7)$ & $26(10)$ & $4.08(0.81)$ & $3.86(0.59)$ & $3.33(0.57)$ & $80.30(3.92)$ & $85.67(3.58)$ & $80.06(4.04)$ \\
\hline
\end{tabular}

cients ranged from 0.92 ( $\mathrm{F}_{0}$ minimum) to 0.99 ( $\mathrm{F}_{0}$ mean). For interjudge reliability, measures of average absolute measurement error ranged from a low of $2.4 \mathrm{~Hz}\left(\mathrm{~F}_{0}\right.$ mean) to a high of $15.55 \mathrm{~Hz}$ $\left(\mathrm{F}_{0}\right.$ range), and correlation coefficients ranged from $0.90\left(\mathrm{~F}_{0} \mathrm{~min}-\right.$ imum) to 0.99 ( $\mathrm{F}_{0}$ mean). For slope, intrajudge reliability yielded a mean measurement error of $0.005 \mathrm{~Hz} / \mathrm{ms}$ with a correlation of 0.95 for the two sets of measures. Interjudge reliability for slope yielded a mean error of $0.007 \mathrm{~Hz} / \mathrm{ms}$ and a correlation of 0.95 .

\section{Data Analysis}

For global $\mathrm{F}_{0}$ measures, a multivariate linear model was fit to each dependent variable in this repeated measures design. All models included the main effects of Condition (Habitual, Loud, Slow), Group (MS, PD, Control), as well as a Condition $\times$ Group interaction. To control for sex differences in dependent measures, gender was included as a covariate in all analyses. A similar model was fit to the dependent measure of focal $\mathrm{F}_{0}$ slope, but this model included an additional main effect of Position (Terminal, Nonterminal) as well as all possible two- and three-way interactions of main effects. Pairwise comparisons were performed based on the fitted models in conjunction with a Tukey-Kramer adjustment for multiple comparisons. A nominal significance level of 0.05 was used in all hypothesis testing.

\section{Results}

\section{Articulatory Rate and SPL}

Table 3 reports articulatory rate and SPL measures. Analyses for articulatory rate indicated a significant Condition effect $[\mathrm{F}(2,36)=70.86, \mathrm{p}<0.0001]$ as well as a Group $\times$ Condition interaction $[\mathrm{F}(4,36)=2.81, \mathrm{p}=$ 0.0395]. The main effect of Group was not significant. Post hoc testing further indicated a reduced articulatory rate for the Slow-Habitual $(\mathrm{p}<0.0001)$ and Slow-Loud $(\mathrm{p}<0.0001)$ contrasts. Articulatory rate also was significantly slower in the Loud versus Habitual condition ( $\mathrm{p}=$ 0.0016). Within each speaker group only the Slow-Habitual and Slow-Loud contrasts were statistically significant. For SPL, there also was a significant Condition effect $[\mathrm{F}(2,36)=123.85, \mathrm{p}<0.0001]$, but no Group effect or Group $\times$ Condition interaction. Post hoc testing indi- cated higher SPLs for the Loud-Habitual and Loud-Slow ( $p<0.0001)$ contrasts. The Habitual-Slow contrast also was significant ( $p=0.0419)$, but the mean difference for these conditions was only about $1 \mathrm{~dB}$.

To summarize, on average, articulatory rate was reduced to about $75 \%$ of Habitual in the Slow condition. The Slow condition further elicited a reduced articulatory rate relative to the Habitual and Loud conditions, and this trend held for 36 of the 40 speakers. The Loud condition elicited about a 5-dB increase in vocal intensity relative to the Habitual and Slow conditions. This trend held for each of the 40 speakers.

\section{$F_{0}$ Measures}

Figure 2 reports $\mathrm{F}_{0}$ mean, minimum, maximum and slope as a function of group and condition. Each symbol represents the average value for an individual speaker. Table 4 reports descriptive statistics for measures of $\mathrm{F}_{0}$ variation as a function of group, sex, and condition.

With the exception of $\mathrm{F}_{0}$ minimum, the main effect of Condition was significant in analyses for all dependent variables. The typical pattern of results was such that $\mathrm{F}_{0}$ measures were highest or greatest in the Loud condition, followed by the Habitual and Slow conditions. For example, collapsing data across groups and speakers, $\mathrm{F}_{0}$ range was greatest in the Loud condition (male mean $=$ $105 \mathrm{~Hz}$; female mean $=196 \mathrm{~Hz}$ ), followed by the Habitual (male mean $=91 \mathrm{~Hz}$; female mean $=172 \mathrm{~Hz})$ and Slow (male mean $=83 \mathrm{~Hz}$; female mean $=141 \mathrm{~Hz}$ ) conditions. For slope, however, measures were greatest or closest to 0 (i.e., indicating shallower slopes) in the Slow condition (male mean $=-0.008 \mathrm{~Hz} / \mathrm{ms}$; female mean $=-0.009 \mathrm{~Hz} /$ $\mathrm{ms}$ ) as compared to the Loud (male mean $=-0.011 \mathrm{~Hz} /$ $\mathrm{ms}$; female mean $=-0.022 \mathrm{~Hz} / \mathrm{ms}$ ) and Habitual (male mean $=-0.014 \mathrm{~Hz} / \mathrm{ms}$; female mean $=-0.020 \mathrm{~Hz} / \mathrm{ms}$ ) conditions. Post hoc tests further indicated that the Habitual-Loud and Loud-Slow comparisons were usually significant $(\mathrm{p}<0.05)$. Many $\mathrm{F}_{0}$ measures also tended to differ in the Habitual and Slow conditions, but this dif- 


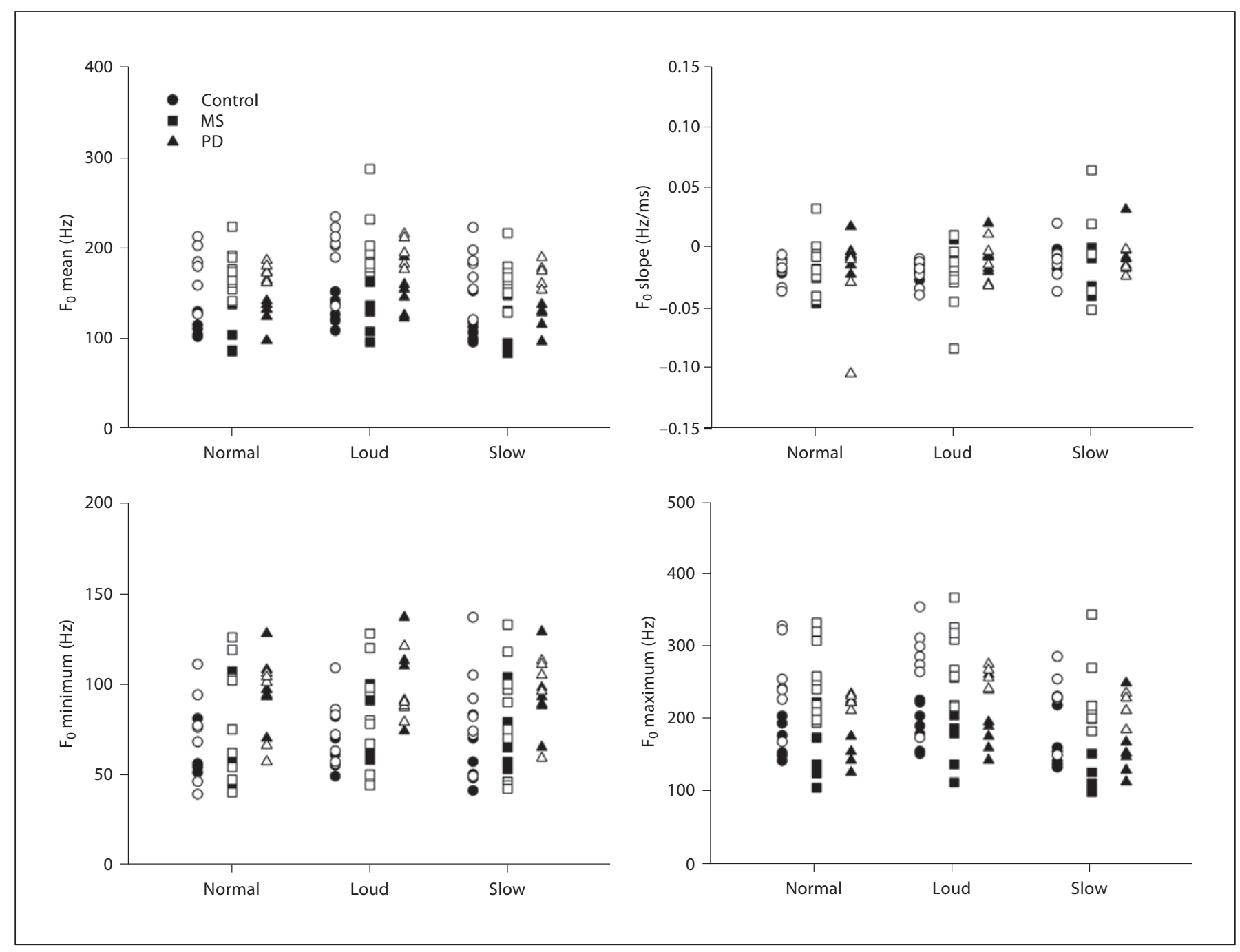

Fig. 2. $\mathrm{F}_{0}$ mean, minimum, maximum and slope data are reported as a function of speaker group and condition. Each symbol represents the average value for an individual speaker. Symbol shape indicates group affiliation, with unfilled and filled symbols corresponding to female and male speakers, respectively.

ference was not always statistically significant. Analyses for slope and $\mathrm{F}_{0}$ range were exceptions. Finally, the main effect of Group was only significant in the statistical analysis for $\mathrm{F}_{0}$ minima $[\mathrm{F}(2,36)=4.69, \mathrm{p}=0.0155]$, where values were highest for the $\mathrm{PD}$ group (male mean $=98 \mathrm{~Hz}$; female mean $=87 \mathrm{~Hz}$ ) followed by the MS (male mean = $69 \mathrm{~Hz}$; female mean $=79 \mathrm{~Hz}$ ) and Control (male mean $=$ $60 \mathrm{~Hz}$; female mean $=73 \mathrm{~Hz}$ ) groups. Post hoc testing indicated that only the PD-Control comparison was significant $(\mathrm{p}=0.0128)$. The Group $\times$ Condition interaction was not significant in any of the analyses.

Upwards of $80 \%$ of speakers followed these group trends. For example, 34/40 speakers used a greater $\mathrm{F}_{0}$ range in the Loud versus Habitual condition, 33/40 speakers used a greater $\mathrm{F}_{0}$ range in the Habitual versus Slow condition, and $37 / 40$ speakers used a greater $\mathrm{F}_{0}$ range in the Loud versus the Slow condition. $\mathrm{F}_{0}$ slope was the exception as only 26 of 40 speakers exhibited a shallower $\mathrm{F}_{0}$ slope in the Slow condition as compared to the Habitual condition. Speakers in all groups departed from the predominant trend or pattern for global $\mathrm{F}_{0}$ slope. Lastly, statistical analyses of focal $F_{0}$ slope data failed to reveal any significant main effects or interactions. As such, these data are not considered further. 
Table 4. Summary statistics in the form of means and standard deviations ( $\mathrm{SD}$, values in parentheses) are reported for measures of $\mathrm{F}_{0}$ variation

\begin{tabular}{|c|c|c|c|c|c|c|c|c|c|c|}
\hline \multirow[t]{2}{*}{ Group } & \multirow[t]{2}{*}{ Sex } & \multicolumn{3}{|l|}{$\mathrm{F}_{0}$ range } & \multicolumn{3}{|l|}{$\mathrm{F}_{0} \mathrm{IQR}$} & \multicolumn{3}{|l|}{$\mathrm{F}_{0} \mathrm{SD}$} \\
\hline & & habitual & loud & slow & habitual & loud & slow & habitual & loud & slow \\
\hline Control & male & $111(27)$ & $129(28)$ & $101(21)$ & $28(12)$ & $35(12)$ & $27(14)$ & $22(7)$ & $26(6)$ & $22(7)$ \\
\hline MS & male & $86(38)$ & $92(32)$ & $73(40)$ & $20(17)$ & $24(9)$ & $17(6)$ & $17(6)$ & $19(7)$ & $15(7)$ \\
\hline $\mathrm{PD}$ & male & 72 (18) & $88(23)$ & $70(29)$ & $17(6)$ & $23(9)$ & $17(9)$ & $14(4)$ & $19(16)$ & $14(7)$ \\
\hline Control & female & $185(62)$ & 209 (52) & $146(34)$ & 36 (19) & $42(17)$ & $30(11)$ & 37 (13) & $42(11)$ & $32(9)$ \\
\hline MS & female & $178(59)$ & $203(52)$ & $148(60)$ & 40 (18) & $44(13)$ & $34(16)$ & 39 (18) & $43(11)$ & 34 (13) \\
\hline PD & female & $141(26)$ & $164(17)$ & 121 (29) & $27(6)$ & $37(6)$ & $26(10)$ & $27(6)$ & $33(3)$ & $27(11)$ \\
\hline
\end{tabular}

IQR = Interquartile range.

\section{Discussion}

An increase in vocal intensity of approximately $5 \mathrm{~dB}$ SPL relative to habitual or typical speech was sufficient to elicit an increase in $\mathrm{F}_{0}$ mean, maximum, range, standard deviation, and interquartile range. These results are consistent with findings reported in previous studies of normal speech and studies of PD [12, 15-19]. Findings also are consistent with a study examining the impact of increased loudness on $\mathrm{F}_{0}$ characteristics for 2 speakers with dysarthria secondary to MS [35]. In contrast, a slowing of articulatory rate to about $75 \%$ of habitual had a very different effect on $\mathrm{F}_{0}$. Relative to the habitual condition, a slower-than-normal articulatory rate was associated with a reduction in $\mathrm{F}_{0}$ mean, maximum and range as well as a more gradually declining $\mathrm{F}_{0}$ across speech runs, as indicated by measures of $\mathrm{F}_{0}$ slope. These findings for the slow condition also support findings from previous studies of normal speech [15, 25-27], and even more importantly extend our understanding of how a slower-than-normal articulatory rate affects utterance-level $\mathrm{F}_{0}$ characteristics for a reading passage produced by speakers with dysarthria.

Measures of $\mathrm{F}_{0}$ variation for speakers with dysarthria were of particular interest owing to their potential contribution to intelligibility. When speakers with PD and MS in the present study increased vocal intensity, utterance-level prosodic variation also increased. In contrast, utterance-level prosodic variation was reduced relative to typical speech when speakers with dysarthria used a slower-than-normal articulatory rate. Table 4 further suggests that when habitual $\mathrm{F}_{0}$ range was the most compressed, a slower-than-normal rate had the least impact on prosodic variation. For example, the average $\mathrm{F}_{0}$ range for male speakers with PD in the habitual condition was $72 \mathrm{~Hz}$, as compared to $111 \mathrm{~Hz}$ for control males and 86 $\mathrm{Hz}$ for the MS males. In the slow condition, $\mathrm{F}_{0}$ range only decreased to an average of $70 \mathrm{~Hz}$ for PD males or about a $3 \%$ decrease as compared to $101 \mathrm{~Hz}$ for control males and $73 \mathrm{~Hz}$ for MS males. A similar trend is evident for MS and PD females. Thus, concerns that articulatory rate reduction will negatively impact on prosodic variation in dysarthria seem to be somewhat mitigated for speakers having a relatively more monotonous habitual speech pattern. Because a variety of techniques may be used clinically to reduce articulatory rate in dysarthria, however, future studies would help to determine whether certain rate reduction techniques are preferred for preserving utterance-level $\mathrm{F}_{0}$ variation.

Results of the current study also support existing studies suggesting that an increased vocal intensity or loud speech may be useful for enhancing $\mathrm{F}_{0}$ variation in dysarthria [12]. Inspection of the data in figure 2 indicates that all of the $\mathrm{F}_{0}$ adjustments for loud speech appear to be within the range of what would be considered appropriate for speakers of both genders. The point is not trivial because speech naturalness or perceived severity may be reduced if global dysarthria treatment techniques are not implemented in such a way that an appropriate overall prosodic profile is achieved $[36,37]$.

Speakers in the present study did not reduce articulatory rate in the loud condition relative to the habitual condition, but other studies have reported that an increased vocal intensity is accompanied by a reduction in articulatory rate as well as enhanced $\mathrm{F}_{0}$ variation in dysarthria [12]. Thus, a slowing of articulatory rate in dysarthria need not preclude the possibility of enhanced $\mathrm{F}_{0}$ variation, if the reduction in rate is accomplished within 
the context of increased vocal loudness. Clear speech also shows promise as a therapeutic technique for simultaneously slowing articulatory rate and enhancing prosodic variation. Studies of clear speech in neurologically normal talkers, for example, suggest that clear speech is associated with enhanced $\mathrm{F}_{0}$ variation, lengthened segment durations and reduced articulatory rate, as well as improved intelligibility [38-41]. The few published studies investigating clear speech in dysarthria also suggest that relative to habitual speech, clear or hyperarticulate speech is associated with improved intelligibility, reduced articulatory rate or lengthened segment durations, and increased phrase or sentence-level $\mathrm{F}_{0}$ variation [42-44]. It remains to be determined whether clear or loud speech is relatively more effective in simultaneously reducing articulatory rate and enhancing or at least maintaining utterance-level $\mathrm{F}_{0}$ variation for speakers with a variety of neurological diagnoses and dysarthrias.

Maximizing intelligibility is an important treatment goal for many patients with dysarthria. Based on the present findings of increased $\mathrm{F}_{0}$ variation in the loud condition and a tendency toward reduced $\mathrm{F}_{0}$ variation in the slow condition relative to habitual speech, it is tempting to conclude that therapeutic techniques focusing on increasing vocal loudness might be preferred to techniques focusing on rate reduction if dysarthria treatment aims to maximize intelligibility. The current study was an investigation of speech production characteristics, however, and future studies are needed to quantitatively evaluate the relationship between perceptual judgments of intelligibility and $\mathrm{F}_{0}$ adjustments accompanying a slowerthan-normal rate and increased loudness for speakers with dysarthria. Intelligibility is a complex construct reflecting at minimum the combined influence of segmental, suprasegmental, linguistic and listener variables. $\mathrm{F}_{0}$ - or prosodic variation - appears to interact with segmental integrity to impact on intelligibility in ways that are only beginning to be understood [e.g., 6, 9]. A variety of studies suggest that a slower-than-normal articulatory rate and increased vocal loudness may impact segmental characteristics in dysarthria. The manner in which these types of segmental adjustments may interact with $\mathrm{F}_{0}$ to ultimately impact perceptual judgments of intelligibility or naturalness in dysarthria requires further study. Studies employing speech resynthesis will likely prove helpful in this regard.

Finally, speakers with MS and PD in the present study were judged to exhibit dysarthria. However, with the exception of measures of $\mathrm{F}_{0}$ minima, there were no group differences in measures of $\mathrm{F}_{0}$ or in how $\mathrm{F}_{0}$ measures were affected by a slower-than-normal rate or increased vocal intensity. The implication is that prosody - at least as indexed by measures of $\mathrm{F}_{0}$ - was only mildly affected for speakers with dysarthria in the current study. Future studies are needed to determine how increased loudness and a slower-than-normal rate affect $\mathrm{F}_{0}$ characteristics in more severe dysarthria.

In conclusion, increased vocal intensity and a slowerthan-normal rate were found to have opposite effects on $\mathrm{F}_{0}$ characteristics for a reading passage produced by speakers with PD, speakers with MS, and healthy controls. An increased vocal intensity was associated with adjustments in measures of $\mathrm{F}_{0}$ variation that have the potential to be beneficial to intelligibility, and a slowerthan-normal rate was associated with changes in measures of $\mathrm{F}_{0}$ variation potentially detrimental to intelligibility. It is important for future studies to determine the relationship - if any - of these types of $\mathrm{F}_{0}$ adjustments to perceptual impressions of intelligibility and or speech naturalness.

\section{Acknowledgments}

We thank Beth Hilczmayer and Erin Szajta for their assistance with the acoustic analyses as well as Miranda Crumb and Grace Liu for their assistance with data reduction and entry. Portions of this study were reported at the 2008 Conference on Motor Speech. Research supported by NIDCD R01DC004689.

\section{References}

1 Binns C, Culling JF: The role of fundamental frequency contours in the perception of speech against interfering speech. J Acoust Soc Am 2007; 122:1765-1776.

2 Bradlow AR, Torretta GM, Pisoni DB: Intelligibility of normal speech. I. Global and fine-grained acoustic-phonetic talker characteristics. Speech Commun 1996;20:255272 .
-3 Bunton K, Kent RD, Kent JF, Duffy JR: The effects of flattening fundamental frequency contours on sentence intelligibility in speakers with dysarthria. Clin Linguist Phon 2001; 15:181-193.

4 Laures J, Weismer G: The effect of a flattened f0 on intelligibility at the sentence-level. J Speech Lang Hear Res1999;42:1148-1156.
5 Massen B, Povel D: The effect of correcting fundamental frequency on the intelligibility of deaf speech and its interaction with temporal aspects. J Acoust Soc Am 1984;76: 1673-1681.

-6 Spitzer SM, Liss JM, Mattys SL: Acoustic cues to lexical segmentation: a study of resynthesized speech. J Acoust Soc Am 2007; 122:3678-3687. 
7 Watson PJ, Schlauch RS: The effect of fundamental frequency on the intelligibility of speech with flattened intonation contours. Am J Speech Lang Pathol 2008;17:348-355.

8 Wingfield A, Lombardi L, Sokol S: Prosodic features and the intelligibility of accelerated speech: syntactic versus periodic segmentation. J Speech Hear Res 1984;27:125-134.

$\checkmark 9$ Bunton K: Fundamental frequency as a perceptual cue for vowel identification in speaker's with Parkinson disease. Folia Phoniatr Logop 2006;58:323-339.

$\checkmark 10$ Kain A, Hosom JP, Niu X, van Santen J, Fried-Oken M, Staehely J: Improving the intelligibility of dysarthric speech. Speech Commun 2007;49:743-459.

11 Duffy JR: Motor Speech Disorders: Substrates, Differential Diagnosis, and Management, ed 2. St. Louis, Mosby, 2005.

12 Yorkston KM, Hakel M, Beukelman DR, Fager S: Evidence for effectiveness of treatment of loudness, rate, or prosody in dysarthria: a systematic review (ANCDS Bulletin Board). J Med Speech Lang Pathol 2007; 15:xi-xxxvi.

-13 Tjaden K, Wilding GE: Rate and loudness manipulations in dysarthria: acoustic and perceptual findings. J Speech Lang Hear Res 2004;47:766-783.

14 Tjaden K, Wilding GE: Effect of rate reduction and increased loudness on acoustic measures of anticipatory coarticulation in multiple sclerosis and Parkinson's disease. J Speech Lang Hear Res 2005;48:261-277.

$\checkmark 15$ Dromey C, Ramig LO: Intentional changes in sound pressure level and rate: their impact on measures of respiration, phonation, and articulation. J Speech Lang Hear Res 1998; 41:1003-1018.

-16 Holmberg EB, Hillman RE, Perkell JS: Glottal airflow and transglottal air pressure measurements for male and female speakers in soft, normal, and loud voice. J Acoust Soc Am 1988;84:511-529.

17 Patel R, Schell KW: The influence of linguistic content on the Lombard effect. J Speech Lang Hear Res 2008;51:209-220.

-18 Stathopoulos ET, Sapienza CM: Respiratory and laryngeal function of women and men during vocal intensity variation. J Speech Hear Res 1993;36:64-75.
19 Stathopoulos ET, Sapienza CM: Developmental changes in laryngeal and respiratory function with variations in sound pressure level. J Speech Lang Hear Res 1997;40:595614.

20 Kleinow J, Smith A, Ramig LO: Speech motor stability in IPD: effects of rate and loudness manipulations. J Speech Lang Hear Res 2001;44:1041-1051.

21 McHenry, MA: The effect of pacing strategies on the variability of speech movement sequences in dysarthria. J Speech Lang Hear Res 2003;46:702-710.

22 McHenry MA, Liss JM: The impact of stimulated vocal loudness of nasalance in dysarthria. J Me Speech Lang Pathol 2006;14:197205.

23 LeDorze G, Dionne L, Ryalls J, Julien M, Ouellet L: The effects of speech and language therapy for a case of dysarthria associated with Parkinson's disease. Eur J Disord Commun 1992;27:313-324.

24 Wang YT, Kent RD, Duffy JR, Thomas JE: Dysarthria in traumatic brain injury: a breath group and intonational analysis. Folia Phoniatr Logop 2005;57:59-89.

25 Cooper WE, Sorensen JM: Fundamental Frequency in Sentence Production. New York, Springer, 1981.

26 Steppling ML, Montgomery AA: Perception and production of rise-fall intonation in American speech. Percept Psychophys 2002; 64;451-461.

27 Ladd DR, Faulkner D, Faulkner H, Schepman A: Constant segmental anchoring of F0 movements under changes in speech rate. Acoust Soc Am 1999;106:1543-1554.

28 Weismer G, Jeng J, Laures JS, Kent R: Acous tic and intelligibility characteristics of sentence production in neurogenic speech disorders. Folia Phoniatr Logop 2001;53:1-18.

29 Milenkovic P: Cspeech, version 4.0, computer program. Madison, University of Wisconsin, 1997.

30 Turner GS, Weismer G: Characteristics of speaking rate in the dysarthria associated with amyotrophic lateral sclerosis. J Speech Hear Res 1993;36:1134-1144

31 Milenkovic P: TF32. Computer program. Madison, University of Wisconsin, 2003

$32 \mathrm{Kim} \mathrm{HH}$ : Monotony of speech production in Parkinson's disease: acoustic entities and their perceptual relations; unpublished $\mathrm{PhD}$ diss University of Wisconsin-Madison, 1994.
33 Lieberman P: Intonation, perception and language. Cambridge, MIT Press, 1967.

$>34$ Lieberman P, Katz W, Jongman A, Zimmerman R, Miller M: Measures of the sentence intonation of read and spontaneous speech in American English. J Acoust Soc Am 1985; 77:649-657.

35 Sapir S, Pawless AA, Ramig LO, Seeley E, Fox C, Corby J: Effects of intensive phonatoryrespiratory treatment (LSVT) on voice in two individuals with multiple sclerosis. J Med Speech Lang Pathol 2001;9:141-151.

36 Liss J: The role of speech perception in motor speech disorders; in Weismer G (ed): Motor Speech Disorders. San Diego, Plural, 2007, pp 187-220.

37 Yorkston K, Beukelman D, Strand E, Bell K: Management of Motor Speech Disorders in Children and Adults. Austin, Pro-Ed, 1999.

-38 Bradlow A, Kraus N, Hayes E: Speaking clearly for children with learning disabilities: sentence perception in noise. J Speech Lang Hear Res 2003;46:80-97.

39 Krause JC, Braida LD: Acoustic properties of naturally produced clear speech at normal speaking rates. J Acoust Soc Am 2004;15: 362-378.

40 Ferguson SH, Kewley-Port D: Talker differences in clear and conversational speech: acoustic characteristics of vowels. J Speech Hear Res 2007;50:1241-1255.

41 Picheny MA, Durlach NI, Braida LD: Speaking clearly for the hard of hearing. II. Acoustic characteristics of clear and conversational speech. J Speech Hear Res 1986;29: 434-446.

-42 Beukelman DR, Fager S, Ullman, C, Hanson E, Logemann J: The impact of speech supplementation and clear speech on the intelligibility and speaking rate of people with traumatic brain injury. J Med Speech Lang Pathol 2002;10:237-242.

$\checkmark 43$ Dromey C: Articulatory kinematics in patients with Parkinson disease using different speech treatment approaches. J Med Speech Lang Pathol 2000;8:155-161.

44 Goberman AM, Elmer LW: Acoustic analysis of clear versus conversational speech in individuals with Parkinson disease. J Commun Disord 2004;38:215-230. 